Enzyme and Microbial Technology, Volume 90, August 2016, Pages 69-75,

DOI: 10.1016/j.enzmictec.2016.05.002

\title{
Environmental stress and elicitors enhance taxol production by endophytic strains of Paraconiothyrium variabile and Epicoccum nigrum
}

\author{
Supunnika Somjaipeng, Angel Medina and Naresh Magan \\ Applied Mycology Group, AgriFood Theme, Cranfield University, \\ Cranfield, Beds MK43 OAL, U.K.
}

Key words: elicitors, water stress, $\mathrm{pH}$, growth, taxol production, enhanced production, pharma products

\begin{abstract}
This study examined the effect of different elicitors (seven, different concentrations) and environmental factors (water activity $\left(\mathrm{a}_{\mathrm{w}}\right), \mathrm{pH}$ ) on taxol production by strains of two endophytic fungi, Paraconiothyrium variabile and Epicoccum nigrum, isolated from temperate yew trees. A defined liquid broth medium was modified with elicitors, solute $\mathrm{a}_{\mathrm{w}}$ depressors at different $\mathrm{pH}$ values. For P. variabile, the best elicitor was salicylic acid at $50 \mathrm{mg} / 1$ which gave a taxol yield of $14.7 \pm 4.8$ $\mu \mathrm{g} / \mathrm{l}$. The study of synergistic effects between elicitor, $\mathrm{a}_{\mathrm{w}}$ and $\mathrm{pH}$ on taxol production showed that the highest yield of taxol $(68.9 \pm 11.9 \mu \mathrm{g} / \mathrm{l})$ was produced under modified ionic stress of $0.98 \mathrm{a}_{\mathrm{w}}(\mathrm{KCl})$ at $\mathrm{pH} 5$ when supplemented with $20 \mathrm{mg} / 1$ of salicylic acid. For E. nigrum, serine was the best elicitor which increased yield significantly (29.6 fold) when KCL was used as the $a_{w}$ depressor $\left(0.98 a_{w}\right)$ at pH 5.0 with $30 \mathrm{mg} / 1$ of serine. The maximum taxol yield produced by E. nigrum was $57.1 \pm 11.8$ $\mu \mathrm{g} / \mathrm{l}$. Surface response models were used to build contour maps to determine the conditions for maximum and marginal conditions for taxol yield in relation to the best elicitor and $\mathrm{a}_{\mathrm{w}}$, and the best $\mathrm{pH}$ for the first time. This will be beneficial for identifying key parameters for improvement of taxol yields by endophytic fungi.
\end{abstract}

Published by Elsevier. This is the Author Accepted Manuscript issued with: Creative Commons Attribution Non-Commercial No Derivatives License (CC:BY:NC:ND 4.0).

The final published version is available online at 10.1016/j.enzmictec.2016.05.002.

Please refer to any applicable publisher terms of use. 


\section{Introduction}

There has been significant interest in the potential for using endophytic fungi isolated from both tropical and temperate yew trees (Taxus species) for the production of the diterpenoid anti-cancer drug taxol. Taxol has also been shown to have potential therapeutic properties against non-cancerous diseases, including neurodegenerative diseases and polycystic kidney disease $[1,2]$. The global market for taxol is large, with Bristol-Myers Squibb having a turnover of $\$ 1.5$ billion in revenue per annum in 2015. Taxol is normally extracted from the bark of the yew tree with $>20 \mathrm{~kg}$ required for every mg of taxol. Thus alternative sources have been sought for the production of taxol, including endophytic fungi.

We recently isolated endophytic strains of two species, Paraconiothyrium variabile and Epicoccum nigrum, from temperate yew trees in the UK which could produce taxol [3]. The strains of $P$. variabile and E. nigrum were found to produce 1.75 and $1.32 \mu \mathrm{g} / 1$ taxol respectively in defined media. The previous study identified the optimum temperature, water activity $\left(\mathrm{a}_{\mathrm{w}}\right)$ and solute type for the taxol yield by the $P$. variabile strain. For this strain optimum growth was at $0.99 \mathrm{a}_{\mathrm{w}}$ and $25^{\circ} \mathrm{C}$. However, optimum taxol yield was $7 \mu \mathrm{g} / 1$ at $0.98 \mathrm{a}_{\mathrm{w}}$ and $20-25^{\circ} \mathrm{C}$.

Because the yields of taxol were in the low $\mu \mathrm{g} / \mathrm{l}$ range, there was interest in evaluating approaches to enhance or stimulate production. For taxol and other secondary metabolites studies have been focused on whether precursors, carbon:nitrogen ratio and C-source, phosphate, trace elements, elicitors or environmental stress may stimulate production [4, 5, 6, 7]. Previously, taxol production was increased 8-fold in a Nigrospora species with elevated concentrations of the basal defined M1D medium in a solid substrate fermentation system [8,9]. Aldred et al. [9] demonstrated that solid substrate fermentation and environmental manipulation could significantly enhance the production of cholesterol lowering drugs such as the squalistatins produced by a Phoma species.

There have been very few detailed studies on the ecophysiology of taxol producing fungi and on optimization conditions for production. This is surprising as this product can be produced via fermentation in the same way as other secondary metabolite products from fungi, such as cyclosporins, statins and indeed penicillin. However, the ecological niches in which fungal groups grow need to be considered in trying to optimize production systems using fungi to try and simulate the conditions in nature [10]. It has also been shown that interacting conditions of water stress, temperature and $\mathrm{pH}$ and even light can impact on both growth and yield of secondary metabolites by filamentous fungi $[6,11,12,13]$. Recent studies with tissue cultures of Taxus chinensis plants revealed that a temperature shift from the optimum for growth enhanced taxol yield. Culturing of such plant cells under water stress with mannitol, sorbitol and polyethylene glycol modified media, resulted in an enhancement of taxol yield $[14,15]$.

Other approaches including elicitation have been examined to try and stimulate biosynthesis of useful metabolites. $\mathrm{Xu}$ et al. [7] used elicitors such as sodium acetate to significantly increase taxol yield from a Fusarium strain. Supplementation of benzoate was also shown to affect the accumulation of taxol by Pestalotiopsis microspore when lowering inorganic phosphate in the culture media [5]. Furthermore, benzoate at $0.01 \mathrm{mM}$ also activated taxol yield by Periconia sp., with an 8-fold yield increase over the control [6]. Other studies have indicated the ability of other elicitors such as phenylalanine and salicylic acid to improve the productivity of fungal taxol or that of plant cell tissue cultures of Taxus species [16, 17].

The objectives of this study were to (a) study the effect of seven different elicitors on taxol yield, (b) examine the interactions between water stress, $\mathrm{pH}$ and the best elicitors on taxol yield by the strains of $P$. variabile and E. nigrum and (c) build models relating the key parameters to predict optimum and marginal conditions for taxol yield for the first time.

\section{Materials and Methods}




\subsection{Fungal strains}

Fungal strains used in this study were the taxol-producing $P$. variabile and E. nigrum isolated from English yew trees (Taxus baccata) [3].

\subsection{Preparation of mycelial inoculum}

The inoculum was prepared from 7-days-old cultures of both strains (P. variabile and E. nigrum) grown on a $2 \%$ milled yew leaf agar medium at $25^{\circ} \mathrm{C}$. Mycelial agar plugs $(5 \mathrm{~mm}$ diameter) were cut from the margin of the growing colony using a sterilized cork borer. Three agar plugs were used as the inoculum in $250 \mathrm{ml}$ of culture broth in 1 litre flasks.

\subsection{Use of elicitors to stimulate taxol yield}

Ammonium acetate, jasmonic acid, phenyl alanine, salicylic acid, serine, silver nitrate and sodium acetate were used as elicitors in this study. Stock solutions were prepared for dissolving each elicitor in water, except for salicyclic acid which was dissolved in ethanol. These were then sterilized by filtration through a $0.22 \mu \mathrm{m}$ filter. Each inducer was added to the M1D broth $\left(\mathrm{Ca}\left(\mathrm{NO}_{3}\right)_{2}, 1.20 \mathrm{mM}\right.$; $\mathrm{KNO}_{3}, 0.79 \mathrm{mM}$; KCl, $0.87 \mathrm{mM}$; $\mathrm{MgSO}_{4}, 3.0 \mathrm{mM}$; $\mathrm{NaH}_{2} \mathrm{PO}_{4} \mathrm{H}_{2} \mathrm{O}, 0.14 \mathrm{mM}$; Sucrose, $87.60 \mathrm{mM}$; Ammonium tartrate, $2.10 \mathrm{mM} ; \mathrm{FeCl}_{3} \mathrm{H}_{2} \mathrm{O}, 7.4 \mu \mathrm{M} ; \mathrm{MnSO}_{4}, 30.0 \mu \mathrm{M} ; \mathrm{ZnSO}_{4} 7 \mathrm{H}_{2} \mathrm{O}, 8.7 \mu \mathrm{M} ; \mathrm{H}_{3} \mathrm{PO}_{4}$, $2.2 \mu \mathrm{M}$; KI, $4.5 \mu \mathrm{M}$; yeast extract $0.25 \mathrm{~g} / 1$, soytone (1g/l), pH 5.5) (Pinkerton and Strobel, 1976) at the different concentration levels shown in Table 1. The cultures were grown in static culture for 21 days at $25^{\circ} \mathrm{C}$. All experiments were repeated once. Three weeks were chosen based on previous temporal studies with Pestalotiopsis microspore which suggested that taxol yield peaked after 2-3 weeks and then declined rapidly [18].

\subsection{Effect of elicitor type, water activity and $\mathrm{pH}$ on taxol yield}

The effects of the best elicitors, $\mathrm{a}_{\mathrm{w}}$ and $\mathrm{pH}$ on taxol yield were studied for both $P$. variabile and E. nigrum. The design consisted of two $\mathrm{a}_{\mathrm{w}}$ levels ( 0.995 and $\left.0.98 \mathrm{a}_{\mathrm{w}}\right)$, and two $\mathrm{pH}$ levels (5 and 6). The inducers selected from the previous experiment were salicylic acid (20 and $50 \mathrm{mg} / \mathrm{l})$ for $P$. variabile and serine (30 and $85 \mathrm{mg} / \mathrm{l}$ ) for E. nigrum. The defined MID base medium detailed previously was used in this study. The $\mathrm{a}_{\mathrm{w}}$ of this medium was adjusted by adding either $\mathrm{KCl}$ or glucose to obtain the target $0.98 \mathrm{a}_{\mathrm{w}}$ level which was checked with the $\mathrm{a}_{\mathrm{w}}$ meter (AquaLab, Decagon Devices, Inc., USA). The initial $\mathrm{pH}$ of the medium was adjusted by using $1 \mathrm{~N} \mathrm{HCl}$ or $1 \mathrm{~N} \mathrm{NaOH}$ to

give the desired $\mathrm{pH}$. Stock solutions of each inducer were prepared by dissolving each one in water or ethanol (salicyclic acid only) and sterilizing by filtration through a $0.22 \mu \mathrm{m}$ filter. Each inducer was added to the M1D broth $(250 \mathrm{ml})$ at the tested concentration. The treatments were incubated at $25^{\circ} \mathrm{C}$ for 21 days. All experiments were repeated once. The cultured media were then extracted for taxol quantification by HPLC and confirmation using LC/MS [3].

\subsection{Fungal taxol extraction}

After 21 days incubation the fungal biomass was separated from the culture broth by filtration. The filtered culture broth was subsequently extracted by adding dichloromethane in two equal volumes to the culture broth [18]. The extracted solvent was evaporated by using the rotary evaporator to dryness at $35^{\circ} \mathrm{C}$ (Eyela, Tokyo, Japan). The dry residue was re-dissolved in $5 \mathrm{ml}$ of $100 \%$ dichloromethane and then passed through a Solid Phase Extraction (SPE) column (silica gel; $15 \mathrm{ml}$ with a bed weight $2 \mathrm{~g}$; Thermo Scientific, UK) which was eluted in a stepwise manner. The elution was carried out starting with $15 \mathrm{ml}$ of $100 \%$ dichloromethane and then continued with $15 \mathrm{ml}$ 
of dichloromethane:ethyl acetate at $1: 1 \mathrm{v} / \mathrm{v}$ and $100 \%$ ethyl acetate. The last two eluents were collected, combined and then evaporated to dryness. The dry residue was dissolved in $1 \mathrm{ml}$ of $100 \%$ methanol. All samples were filtered through a $0.22 \mu \mathrm{m}$ nylon filter before analysis with HPLC and LC/MS. The standard taxol (Paclitaxel) was purchased from SIGMA and used for comparison in all experiments.

\subsection{Quantification of taxol}

Taxol in samples were analyzed by HPLC (Algilent 1200, Agilent Technologies, USA) with a C18 analysis column (Agilent Zorbax Eclipse, Part No. 990967-902). Fifty microlitres of sample was injected each time and detected at $230 \mathrm{~nm}$. The mobile phase was methanol:water $(80: 20 \mathrm{v} / \mathrm{v})$ at a flow rate of $1.0 \mathrm{ml} / \mathrm{min}$. LC/MS was used for confirmation of both standards and treatment samples as described in Somjaipeng et al. [3].

\subsection{Statistical analysis}

The effect of the experimental factors on the taxol yield was analysed statistically by using MINITAB version 16.0 (Minitab Inc., USA). When assumptions of normality and equal variance were met, ANOVA was adopted to test for significant differences in response among the studied treatments. Post-hoc inter factor differences were calculated with Tukey multiple comparison tests. If these assumptions of a parametric test were violated, the significant differences were assessed using Kruskal-Wallis nonparametric ANOVA at statistical significant level of $\mathrm{P}<0.05$. Post-hoc inter factor differences were calculated with Dunn's multiple comparison nonparametric tests. Bonferroni correction was used to keep the Bonferroni individual alpha $=0.05$.

\section{Results}

\subsection{Effect of different elicitors on taxol production by the two endophytic fungi}

Figure 1 shows the effect of the different elicitors, at different concentrations, on the taxol yield by $P$. variabile. There was a significant increase in taxol production in all the treatments when compared to the control. Supplementing the media with salicylic acid gave the most significant increase in yield by this endophytic strain. The highest taxol production $(14.7 \pm 4.8 \mu \mathrm{g} / \mathrm{l})$ was obtained after induction with salicylic acid at $50 \mathrm{mg} / \mathrm{l}$. Phenyl alanine-supplemented media had least effect on taxol yield by $P$. variabile. The increase or decrease in taxol yield varied with type of elicitor used. For some there was an increase in taxol yield as concentration was increased (e.g. jasmonic acid), while for many of the others there was a decrease (e.g. salicyclic acid, serine, sodium acetate).

Figure 2 shows the effect on taxol yield by the endophytic strain of E. nigrum. For this strain maximum taxol yield was obtained with serine $(39.8 \pm 18.6 \mu \mathrm{g} / \mathrm{l})$ elicitor at $85 \mathrm{mg} / \mathrm{l}$, while silver nitrate and acetic ammonium increased yields to a lesser extent. Again, threshold concentrations of different elicitors for maximum taxol yield varied.

\subsection{Effect of the best elicitors, water activity and pH interactions on taxol production by the two endophytic strains}

Further studies were carried out to examine the interaction between the impact of the best elicitor identified, combined with changes in water stress and $\mathrm{pH}$ values on taxol yield. Figure 3 shows the effect of these three-way interactions on taxol production. There was a significant improvement in taxol yield by $P$. variabile when using the ionic solute $\mathrm{KCl}$ as the $\mathrm{a}_{\mathrm{w}}$ depressor 
combined with salicylic acid at $20 \mathrm{mg} / \mathrm{l}$. This gave the highest taxol yield regardless of the cultivation $\mathrm{pH}$ used. However, $\mathrm{pH} 5$ was more favourable with a maximum yield of $68.9 \pm 11.9 \mu \mathrm{g} / 1$ (see Figure $3 \mathrm{a}$ ). This was a 10.3 fold increase when compared with the non-modified $\mathrm{a}_{\mathrm{w}}$ conditions. The difference in taxol yield was significant with different concentrations of salicylic acid under acidic condition at $\mathrm{pH} 5$, whereas there was no significant effect at $\mathrm{pH} 6$ (Figure 3b). When the nonionic solute glucose was used as the $\mathrm{a}_{\mathrm{w}}$ depressor, practically no taxol production was observed. The dry weights of mycelium were also examined as an indicator of the ability to grow in the presence of the inducer. There was a noticeable reduction in the mycelial biomass when taxol yield increased.

Figure 4 shows the effect of these interacting treatment conditions on taxol production by $E$. nigrum. The higher taxol yield was obtained at pH $5(57.1 \pm 11.8 \mu \mathrm{g} / 1)$ in the medium modified to $0.98 \mathrm{a}_{\mathrm{w}}$ with the ionic solute $\mathrm{KCl}+30 \mathrm{mg} / \mathrm{l}$ of serine as the elicitor (Figure $4 \mathrm{a}$ ). The difference in the taxol production between this and the non-modified $\mathrm{a}_{\mathrm{w}}$ condition was approx. 8.5 times. Taxol yields were again not significantly improved when a non-ionic solute such as glucose or sorbitol were used to modify the $a_{w}$ of the media. Within the different concentrations of serine used at $\mathrm{pH} 6$ there was no significant effects on taxol yield (Figure $4 \mathrm{~b}$ ). The different concentrations of serine had no influence on the fungal biomass dry weight of E. nigrum. However, cultures with sorbitol-modified media had more mycelial biomass.

\subsection{Modelling the effect of salicylic acid, $p H$ and $a_{w}$ on taxol production in liquid cultures of $P$. variabile}

Statistical analysis was extended to evaluate the effect of salicylic acid, $\mathrm{pH}$ and $\mathrm{a}_{\mathrm{w}}$ on taxol yield in the defined liquid M1D cultures of $P$. variabile when $\mathrm{KCl}$ was used to modify $\mathrm{a}_{\mathrm{w}}$. An ANOVA analysis was carried out on the experimental data (Table 2). Among the quantitative variables examined, all three individually, and their interactions had a significant effect on taxol yield within the range used in this study $(\mathrm{P}<0.05)$. After the collected data were fitted, a first-order model with interaction in terms of the actual factors for taxol yield was developed as shown below:

$\begin{aligned} \text { Taxol amount }= & 43122.4-5443.54 p H-222.997 \text { saliclylic acid }-43771.2 a_{w} \\ & +5525.63 p H * a_{w}+226.48 \text { salicylic acid } * a_{w}\end{aligned}$

The main effects plot is useful in the practical interpretation of the results. In terms of the screening experiment, these plots can be used to compare the changes in the mean level to examine the direction of the response in relation to the tested level of factors providing the information for the subsequent experiment. Figure 5 represents the main effect plots of $\mathrm{pH}, \mathrm{a}_{\mathrm{w}}$ and salicylic acid concentration in term of experimental data. A recommended setting of factor levels to achieve a high response was obtained. Better yield could be achieved by choosing a relatively more acidic $\mathrm{pH}$ level, setting the salicylic acid concentration at a lower level and modifying the $\mathrm{a}_{\mathrm{w}}$ of the culture broth.

Figure 6a presents contour plots of the interaction between $\mathrm{pH} \times \mathrm{a}_{\mathrm{w}}$ on taxol yield when the level of salicylic concentration was held at a fixed level $(20 \mathrm{mg} / \mathrm{l})$. An increasing trend in yield with a slight increase in water stress was observed. Moreover, when the water stress is increased, the impact of $\mathrm{pH}$ on responses became more significant. It seemed that the response depended almost entirely on $a_{w}$. This finding is in good agreement with the high $F$ value of $a_{w}(F$ value=34.94). The higher the $\mathrm{F}$ value the more impact of the particular parameter. Error! Reference source not found.Changing $\mathrm{pH}$ from 5.0 to 6.0 produced more change in taxol yield when $\mathrm{a}_{\mathrm{w}}=0.980$ than when $\mathrm{a}_{\mathrm{w}}=0.985$.

Figure $6 \mathrm{~b}$ shows the interaction between increasing water stress and salicylic acid concentrations. It appeared that the effect of $\mathrm{a}_{\mathrm{w}}$ as a factor was clearly predominant and impacted on the relative taxol production response. Under water stress, the concentration of salicylic acid had a 
more important impact on the response. This was confirmed with the higher $F$ value of $\mathrm{a}_{\mathrm{w}}$. Changing the concentration of salicylic acid from 20 to $50 \mathrm{mg} / 1$ resulted in a much smaller change in taxol yield when $\mathrm{a}_{\mathrm{w}}$ was 0.984 than when $\mathrm{a}_{\mathrm{w}}$ was 0.98 .

\subsection{Modelling the effect of serine, $\mathrm{pH}$ and $a_{w}$ on taxol production in liquid cultures of E. nigrum.}

Evaluation of the effect of serine, $\mathrm{pH}$ and $\mathrm{a}_{\mathrm{w}}$ on taxol production in M1D liquid cultures of $E$. nigrum was also investigated when $\mathrm{KCl}$ was used to modify the $\mathrm{a}_{\mathrm{w}}$. Normality of the distribution of the population was tested using the Kolmogorov-Smirnov test. The test revealed that the response variable was not normally distributed and needed to be normalized by transformation prior to analyses. The data sets were transformed by the Johnson transformations $(\mathrm{P}>0.05)$. The original data sets of taxol yields were thus transformed according to the following equation:

$$
Y^{*}=-0.786458+0.502649 \times \operatorname{Asinh}\left(\frac{(x-4.74745)}{0.690764}\right)
$$

In the equation, $Y^{*}$ represents the transformed taxol yield and $x$ represents the original data.

The back-transformed data were calculated from the equation below:

$$
y=4.74745+\left(0.345382 e^{\left(\frac{\left(Y^{*}+0.786458\right)}{0.502649}\right)}\right)-\left(0.345382 e^{\left(-\frac{\left(Y^{*}+0.786458\right)}{0.502649}\right)}\right)
$$

where $y$ represents back-transformed data, $Y^{*}$ represents the transformed taxol yield.

An ANOVA analysis was carried out on the experimental data (Table 2). All three of the studied factors including $\mathrm{pH}$, serine concentration and $\mathrm{a}_{\mathrm{w}}$ had a significant effect on taxol yield within the range used in this study $(\mathrm{P}<0.05)$. Moreover, there was a significant effect of the interaction between serine concentration and $\mathrm{a}_{\mathrm{w}}(\mathrm{P}<0.05)$.

The first-order model with interaction in terms of the actual factors for taxol yield was developed as shown below:

$$
Y^{*}=548.304-0.648795 p H-7.79362 \text { serine }+7.903652 a_{w}+7.90365 \text { serine } * a_{w} \quad 4
$$

In the equation, $Y^{*}$ represents the transformed taxol amount.

The main effects plot of $\mathrm{pH}, \mathrm{a}_{\mathrm{w}}$ and serine concentration in term of back-transformed data is shown in Figure 7. The results showed that with the decrease in $\mathrm{pH}$ level, a slight increase in water stress and a lower serine concentration provided the increasing trend in taxol yield. $\mathrm{pH}$ did not appear to be a major factor in taxol production in this case.

Figure 8 presents the contour plot of the effect of serine concentration $\mathrm{x} \mathrm{a}_{\mathrm{w}}$ on taxol yield when $\mathrm{pH}$ was held at 5.0 for E. nigrum. There was a small change in taxol yield when cultured under more freely available water conditions $\left(>0.984 \mathrm{a}_{\mathrm{w}}\right)$ than at $0.98 \mathrm{a}_{\mathrm{w}}$. However, an increasing trend in yield with a decrease in serine concentration stress was observed (from 85 to $30 \mathrm{mg} / \mathrm{l})$. Thus, at lower levels of serine, the impact of water stress was more significant. The use of an elicitor had a stronger effect with E. nigrum than with P. variabile. This was confirmed with the high $F$ value of serine concentration $(F$ value $=41.25)$.

\section{Discussion}

The interaction between environmental factors is one of the critical considerations to enhance the production of secondary metabolites by fungi [19, 20, 21]. This study has provided some approaches which can be used for increasing taxol yield by examining interactions between temperature, $\mathrm{a}_{\mathrm{w}}$, solute type, $\mathrm{pH}$ and elicitor. 
Previously Somjaipeng et al. [3] showed that the optimum environmental conditions for growth of $P$. variabile and that of taxol production were slightly different. Generally, the $\mathrm{a}_{\mathrm{w}}$ range for production was from 0.96 to $0.995 \mathrm{a}_{\mathrm{w}}$ and $25^{\circ} \mathrm{C}$. However, taxol yield was increased under slight water stress $\left(0.98 \mathrm{a}_{\mathrm{w}}\right)$ when compared with the treatment where water was freely available $\left(0.99 \mathrm{a}_{\mathrm{w}}\right)$, regardless of temperature. This suggests that some slight ecophysiological manipulation of growth conditions may stimulate secondary metabolite production, including taxol. Previously, Baxter et al. [11] found that the optimum $a_{w}$ for growth of a Phoma sp. which produced the cholesterol lowering metabolite squalistatin S1, was at $0.995 \mathrm{a}_{\mathrm{w}}$, while $0.990-0.980 \mathrm{a}_{\mathrm{w}}$ was optimum for $\mathrm{S}$. In addition, Aldred et al. [9] used solid substrate systems and obtained similar results with the Phoma species. However, they found best $\mathrm{S} 1$ production at $0.96 \mathrm{a}_{\mathrm{w}}$. In contrast, the maximum growth rate was found at 0.998-0.99 $\mathrm{a}_{\mathrm{w}}$. These studies were in natural heterogenous cereal-based substrates and not defined media.

The problems of using endophytic fungi to produce taxol under optimized fermentation processes are the low and unstable productivity. This was also observed for the endophytic strains isolated from the temperate yew trees which produced taxol [3]. The productivity issues found for these endophytic fungi in vitro may be independent of the natural habitat which they occupy in their host plants, where they are more protected from environmental fluxes [22]. There was certainly thus a need to examine whether more stable enhanced production could be achieved using elicitors and interacting environmental conditions.

It has been suggested previously that addition of low concentrations of elicitor compounds such as carbohydrates can bring about physiological changes in microorganisms resulting an increased production of secondary metabolites, enzymes or anti-microbials [23, 24, 25, 26]. Studies with Penicillium chrysogenum and oligosaccharide elicitors resulted in significant increases in penicillin production [23, 27]. Increases in bacitracin A production was also observed with Bacillus lichenformis oligoguluronate and mannan oligosaccharides [25]. These studies suggested that the elicitation mechanism may be operative at a transcription level, although the metabolic pathways and cascade of events, both intra- and extra-cellular levels, have not yet been determined. However, Reffatti et al. [26] found significant proteomic shifts in response to these elicitors.

Some of the elicitors used in the present study were able to increase taxol yield by $P$. variabile when compared with the untreated control cultures. Salicylic acid affected the production of taxol most significantly. Salicylic acid has been previously shown to elicit an increase in taxol yield in suspension plant cell culture of Taxus sp. [1, 18, 28, 29, 30]. Recently, Soliman and Raizada [17] reported the significant enhancement in taxol yield (2x) from Praconiothyrium SSM001 when supplemented with salicylic acid. The biosynthesis of secondary metabolites in plants, including taxol, is widely accepted as the chemical defence responses to counter infection by plant pathogens. The infection by plant pathogens was reported to activate signalling molecules including salicylic acid [31]. This then activates the plant defence system by accumulating the anti-plant pathogen agents. This could be another explanation for the elicitation properties of salicylic acid increasing taxol yield obtained from endophytic fungi in this study. The threshold concentrations of different elicitors necessary may differ based on the results obtained in the present studies. For some compounds, as the concentration was increased the taxol yield was increased. For others, higher concentrations decreased taxol yield. More studies may be required to better understand the threshold range for different elicitors as well as the temporal effect on secondary metabolite production, 
including taxol. Some studies have suggested that maximum taxol yield occurs after 14-21 days for endophytes before decreasing markedly [18].

For E. nigrum, a different elicitor was found to increase taxol production in the defined M1D broth medium. The serine-induced conditions stimulated the most taxol biosynthesis and yield. In the presence of serine, previous reports have shown a significant increase in taxol yield, but only in plant cell cultures of Taxus cuspidate [32]. However, limited information on the influence of such amino acids on taxol production by endophytic fungi is available.

Under modified $\mathrm{a}_{\mathrm{w}}$ conditions with $\mathrm{KCl}\left(0.98 \mathrm{a}_{\mathrm{w}}\right)$ at $\mathrm{pH} 5$, the taxol yield by $P$. variabile and $E$. nigrum was significantly increased when decreasing the concentration of salicylic acid to $20 \mathrm{mg} / \mathrm{l}$ and serine to $30 \mathrm{mg} / \mathrm{l}$, respectively. The induction under non-modified $\mathrm{a}_{\mathrm{w}}$ conditions resulted in very low production, although the elicitor was used. This finding is similar to some previous findings that taxol production by endophytic fungi was significantly reduced by repeated sub-culturing on defined artificial media in vitro.

Similar optimum $\mathrm{pH}$ conditions of 5.0 for taxol production and growth of $P$. variabile and E. nigrum was found in this study. Interestingly, with water stress effects on mycelial growth, there was a slight shift in taxol yield in the presence of the elicitor. Fungal biomass was optimum at $0.99-0.98 \mathrm{a}_{\mathrm{w}}$ while taxol production was at $0.98 \mathrm{a}_{\mathrm{w}}$. This suggests that there may be an interaction effect of slight modifications of growth due to water stress with the presence of an elicitor which may stimulate taxol biosynthesis. Good agreement was obtained between the observed and predicted results when evaluating the effect of elicitor, $\mathrm{pH}$ and $\mathrm{a}_{\mathrm{w}}$ on taxol yield from both strains. This study showed that the elicitors combined with mild water stress conditions $\left(0.98 \mathrm{a}_{\mathrm{w}}\right)$, enhanced taxol yield significantly. It has been previously shown that taxol is very stable over the $\mathrm{pH}$ range of 3-5 [33]. Studies with toxic secondary metabolites (mycotoxins) by Sanchis et al. [34] found that when examining optimum and marginal conditions of $\mathrm{a}_{\mathrm{w}}$ and temperature for growth, secondary metabolite production optima were very different. The optimum conditions for fumonisin production by Fusarium verticillioides were found at $0.97 \mathrm{a}_{\mathrm{w}}$, while the most favourable conditions for growth of this strain was at $0.98-0.96 \mathrm{a}_{\mathrm{w}}$.

\section{Conclusions}

In summary, this study has shown that elicitors can be utilised to stimulate and enhance fungal taxol yield successfully for $P$. variabile by adding salicylic acid $(20 \mathrm{mg} / \mathrm{l})$ and for $E$. nigrum by the addition of serine $(30 \mathrm{mg} / \mathrm{l})$. By combining modified $\mathrm{a}_{\mathrm{w}}$ stress with the ionic solute $\mathrm{KCl}\left(0.98 \mathrm{a}_{\mathrm{w}}\right)$ at $\mathrm{pH} 5$ and supplementation with these concentrations respectively, resulted in a significant stimulation in taxol yield by these two strains isolated from temperate yew trees. This suggests that it is possible to improve production of plantderived bioactive compounds such as taxol by endophytic fungi using these three-way interacting conditions. The modelling also shows the relative ecological conditions for optimum and marginal taxol biosynthesis for the first time.

\section{Acknowledgements}

SS is grateful to the Royal Thai Government for financial support to carry out this work. 


\section{References}

1. Y. Wang, J. Wu, Y. Yuan, Salicylic acid-induced taxol production and isopentenyl pyrophosphate biosynthesis in suspension cultures of Taxus chinensis var. mairei, Cell Biol. Int. 31 (10) (2007) 1179-1183.

2. B. Zhang, A. Maiti, S. Shively, F. Lakhani, G. McDonald-Jones, J. Bruce, E.B. Lee, S.X. Xie, S. Joyce, C. Li, P.M. Toleikis, V.M. Lee, J.Q. Trojanowski, Microtubule-binding drugs offset the sequestration by stabilizing microtubules and reversing fast axonal transport deficits in a tauopathy model, Proc. Nat. Acad. Sci. USA 102 (1) (2005) 227-231.

3. S. Somjaipeng, A. Medina, H. Kwaśna, O.J. Ortiz, N. Magan, Isolation, identification, and ecology of growth and taxol production by an endophytic strain of Paraconiothyrium variabile from English yew trees (Taxus baccata), Fungal Biol. 119 (2015) 1022-1031.

4. J.Y. Li, R.S. Sidhu, A. Bollon, G.A. Strobel, Stimulation of taxol production in liquid cultures of Pestalotiopsis microspora, Mycol. Res. 102 (1998) 461-464.

5. J.Y. Li, R.S. Sidhu, E.J. Ford, D.M. Long, W.M. Hess, G.A. Strobel, The induction of taxol production in the endophytic fungus-Periconia sp from Torreya grandifolia, J. Indust. Microbiol. Biotech. 20 (1998) 259-264.

6. R. Parra, D. Aldred, N. Magan, Medium optimization for the production of the secondary metabolite squalestatin S1 by a Phoma sp. combining orthogonal design and response surface methodology, Enzym. Microbial. Technol. 37 (2005) 704-711.

7. F. Xu, W. Tao, L. Cheng, L. Guo, Strain improvement and optimization of the media of taxolproducing fungus Fusarium maire, Biochem. Eng. J. 31 (2006) 67-73.

8. J. Ruiz-Sanchez, Z.R. Flores-Bustamante, L. Dendooven, E. Favela-Torres, G. Soca-Chafre, J. Galindez-Mayer, L.B. Flores-Cotera, A comparative study of taxol production in liquid and solid-state fermentation with Nigrospora sp. a fungus isolated from Taxus globosa. J. Appl. Microbiol. 109 (6) (2010) 2144-2150.

9. D. Aldred, N. Magan, B. Lane, Influence of water activity and nutrient type on in vitro growth of surface cultures and production of the pharmaceutical metabolite squalestatin S1 by a Phoma sp., J. Appl. Microbiol. 87 (2000) 842-848.

10. D. Aldred, J. Penn, N. Magan, Water availability and metabolomic profiles of Epicoccum nigrum and Sarophorum palmicola grown in solid substrate fermentation systems. The Mycologist 19 (2005) 18-23.

11. C.J. Baxter, N. Magan, B. Lane, H.G. Wildman, H. G., Influence of water activity and temperature on in vitro growth of surface cultures of a Phoma sp. and production of the pharmaceutical metabolites, squalestatins S1 and S2, Appl. Microbiol. Biotechnol. 49, (1998) 328-332.

12. R. Parra, D. Aldred, D.B. Archer, N. Magan, Water activity, solute and temperature modify growth and spore production of wild type and genetically engineered Aspergillus niger strains, Enzyme Microb. Technol. 35 (2-3) (2004) 232-237.

13. N. Magan, Fungi in extreme environments. Chapter 6 In Environmental and Microbial Relationships, 2nd Edition, The MYCOTA IV, eds. CP Kubicek, IS Druzhinina. Springer Velag, Berlin, (2007) 85-103.

14. H. Choi, S. Kim, J.S. Son, S.S. Hong, H.S. Lee, I.S. Chung, H.J. Lee, Intermittent maltose feeding enhances paclitaxel production in suspension culture of Taxus chinensis cells, Biotech. Letts. 22, (2000) 1793-1796.

15. S. Kim, H. Choi, J. Kim, H. Lee, S. Hong, Effect of osmotic pressure on paclitaxel production in suspension cell cultures of Taxus chinensis, Enzyme Microb. Technol. 28, (2-3) (2001) 202209. 
16. C. Veeresham, R. Mamatha, C.P. Babu, K. Srisilam, C.K. Kokate, Production of taxol and its analogues from cell cultures of Taxus wallichiana. Pharm. Biol. 41 (2003) 426-430.

17. S.S.M. Soliman, M.N. Raizada, Interactions between co-habitating fungi elicit synthesis of Taxol from an endophytic fungus in host Taxus plants", Front. Microbiol. 4 (2013), 3 doi: 10.3389/fmicb.2013.00003

18. G. Strobel, X. Yang, J. Sears, R. Kramer, R.S. Sidhu, W.M. Hess, Taxol from Pestalotiopsis microspora, an endophytic fungus of Taxus wallachiana, Microbiol. 142 (2) (1996) 435-440.

19. J. Deacon, Fungal biology (2006), Blackwell Publishing, England.

20. M.J. Carlile, S.C. Watkinsom, G.W. Gooday, The fungi, (2001) Academic Press, Great Britain.

21. N. Magan, D. Aldred, Post-harvest control strategies: Minimizing mycotoxins in the food chain, Int J. Food Microbiol. 119 (1-2) (2007) 131-139.

22. S. Kusari, C. Hertweck, M. Spiteller, Chemical ecology of endophytic fungi: Origins of secondary metabolites, Chem. Biol. 19 (7) (2012) 792-798.

23. B. Ariyo, C. Bucke, T. Keshavarz, Alginate oligopsaccharides as enhancers of penicillin production in cultures of Pencillium chrysogenum, Biotech. Bioeng. 53 (1997) 17-20.

24. T. Murphy, I. Roy, K. Dixon, T. Kesharvarz, Effect of oligosaccharide elicitors on bacitracin A production and evidence of transcriptional control. J. Biotech. 131 (2007) 397-403.

25. T. Murphy, R. Parra, R. Radman, I. Roy, K. Dixon, T. Keshavarz, Novel application of oligosaccharides as elicitors for the enhance ment of bacitracin A production in cultures of Bacillus lichenformis. Enzyme Microb. Technol. 40 (2007) 1518-1523.

26. P.F. Reffatti, I. Roy, M. Odell, T. Keshavarz, Proteomics analysis of Bacillus licheniformis in response to oligosaccharides elicitors, Enzyme Microb. Technol. 61-62, (2014) 61-66.

27. R. Radman, C. Bucke, T. Keshavarz, Elicitor effects on Penicillium chrysogenum morphology in submerged cultures. Biotech. Appl. Biochem. 40 (2004) 229-233.

28. Q.Z. Miao, Z.J. Wei, Y.J. Yuan, Study on the effects of salicylic acid on taxol biosynthesis, Chinese J. Biotech. 16 (4) (2000) 509-513.

29. A.Y. Khosroushahi, M. Valizadeh, A. Ghasempour, M. Khosrowshahli, H. Naghdibadi, M.R. Dadpour, Y. Omidi, Improved Taxol production by combination of inducing factors in suspension cell culture of Taxus baccata, Cell Biol. Int. 30 (3) (2006) 262-269.

30. A. Rezai, F. Ghanati, M. Behmanesh, M. Mokhtari-Dizaji, Ultrasound-potentiated salicyclic acid induced physiological effects and production of taxol in hazelnut (Corylus avellana L.) cell culture, Ultrasound Med. Biol. 37 (11) (2011) 1938-1947.

31. R. Bari, J.D.G. Jones, Role of plant hormones in plant defence responses, Plant Mol. Biol. 69 (4) (XXXX) 473-488.

32. A.G. Fett-Neto, S.J. Melanson, S.A. Nicholson, J.J. Pennington, F. Di Cosmo, Improved taxol yield by aromatic carboxylic acid and amino acid feeding to cell cultures of Taxus cuspidata, Biotech. Bioeng. 44 (8) (1994) 967-971.

33. S.K. Dordumo, H.M. Burt. Solubility and stability of taxol: effects of buffers and cyclodextrins. Int. J. Pharmaceutics 133 (1996) 191-201.

34. S. Marin, N. Magan, A.J. Ramos, V. Sanchis, Fumonisin-producing strains of Fusarium: A review of their ecophysiology, J. Food Protec. 67 (2004) 1792-1805. 
Table 1. The different concentration levels of elicitors used in the experiments.

\begin{tabular}{llll}
\hline \multicolumn{1}{c}{ Types of elicitors } & \multicolumn{3}{c}{ Levels (mg/l) } \\
\hline Acetic ammonium & 0.5 & 1 & 5 \\
Jasmonic acid & 210 & 1051 & 3154 \\
Phenylalanine & 1 & 5 & 10 \\
Salicylic acid & 50 & 100 & 150 \\
Serine & 85 & 100 & 150 \\
Silver nitrate & 1 & 2 & 3 \\
Sodium acetate & 4 & 123 & 410 \\
\hline
\end{tabular}

Table 2. Statistical analyses of the experimental data using analysis of variance for the individual and two-way interacting factor on taxol production by $P$. variabile

\begin{tabular}{lcccc}
\hline Source & DF & $\begin{array}{l}\text { Mean } \\
\text { square }\end{array}$ & F value & P value \\
\hline Main effects & 3 & 2328.9 & 18.24 & 0.000 \\
$\mathrm{pH}$ & 1 & 1281.2 & 10.04 & 0.005 \\
Salicylic acid & 1 & 1244.3 & 9.75 & 0.006 \\
$\mathrm{a}_{\mathrm{w}}$ & 1 & 4461.0 & 34.94 & 0.000 \\
2-Way & 2 & 1438.1 & 11.26 & 0.001 \\
interactions & & & & \\
pH*aw & 1 & 1145.0 & 8.97 & 0.001 \\
Salicylic acid*a $\mathrm{a}_{\mathrm{w}}$ & 1 & 1731.2 & 13.56 & 0.008 \\
Lack of fit & 2 & 177.6 & 1.46 & 0.261 \\
\hline
\end{tabular}


Table 3. Statistical analyses of the experimental data using analysis of variance for the transformed taxol yield data by E. nigrum on a define medium with different individual or two-way interactions.

\begin{tabular}{lcccc}
\hline Source & DF & $\begin{array}{l}\text { Mean } \\
\text { square }\end{array}$ & F value & P value \\
& \multicolumn{5}{l}{$\begin{array}{l} \\
\text { Main effects }\end{array}$} & 3 & 6.1660 & 17.53 & 0.000 \\
$\mathrm{pH}$ & 1 & 2.5256 & 7.18 & 0.015 \\
Serine & 1 & 14.5249 & 41.28 & 0.000 \\
$\mathrm{a}_{\mathrm{w}}$ & 1 & 1.4474 & 4.11 & 0.055 \\
2-Way & 2 & 7.0862 & 20.14 & 0.000 \\
interactions & & & & \\
Serine* $\mathrm{a}_{\mathrm{w}}$ & 1 & 7.0862 & 201.4 & 0.000 \\
Lack of fit & 2 & 0.6727 & 2.31 & 0.116 \\
\hline
\end{tabular}




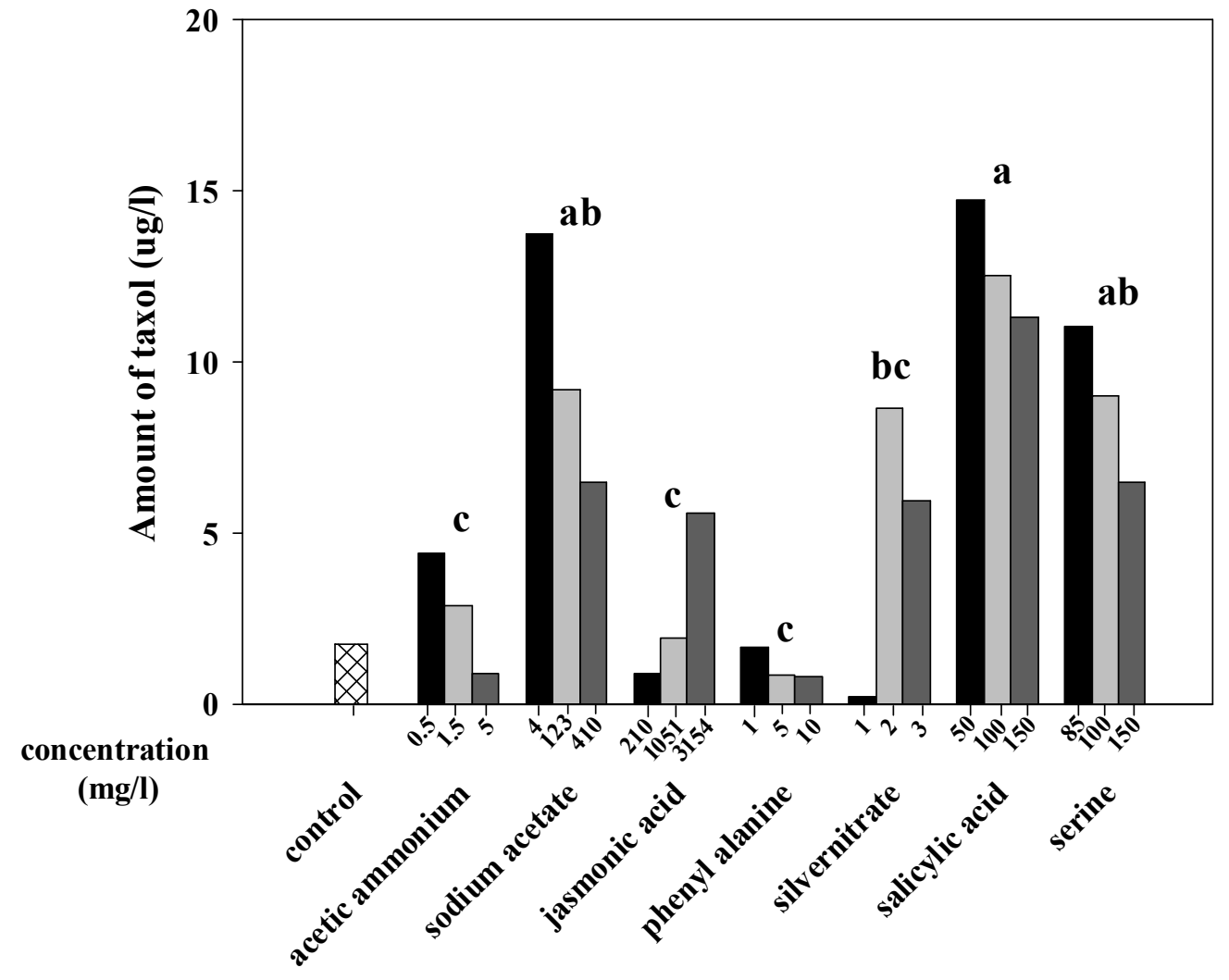

Figure 1 Effect of different concentrations of elicitors on taxol yield $(\mu \mathrm{g} / 1)$ by $P$. variabile in a defined medium. Treatments with different letters are significantly different. Taxol yield in the control defined medium (M1D) alone is included for comparison. 


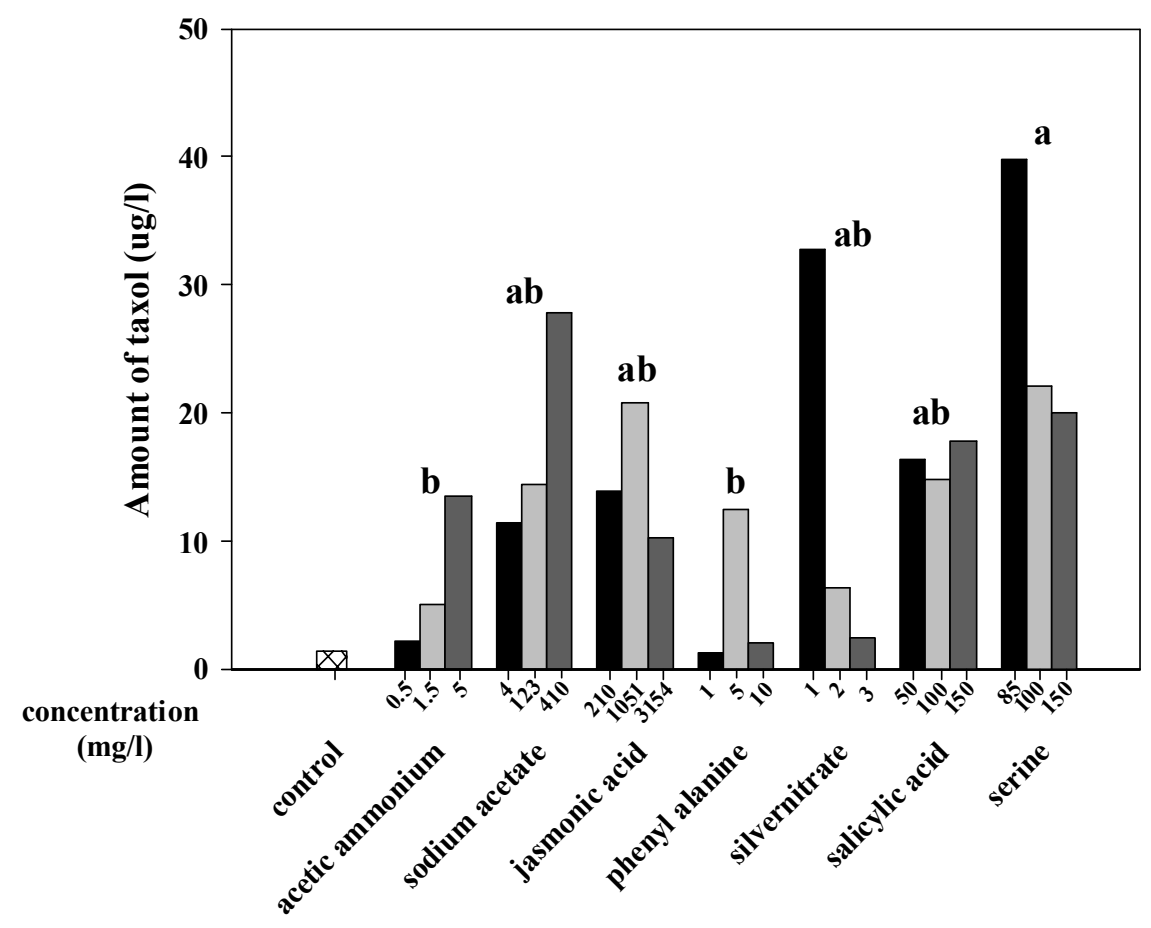

Figure 2 Effect of different concentrations of elicitors on taxol yield $(\mu \mathrm{g} / \mathrm{l})$ by E. nigrum on a defined medium. Treatments with different letters are significantly different. Taxol yield in the control defined medium (M1D) alone is included for comparison. 
(a) $\mathrm{pH}$

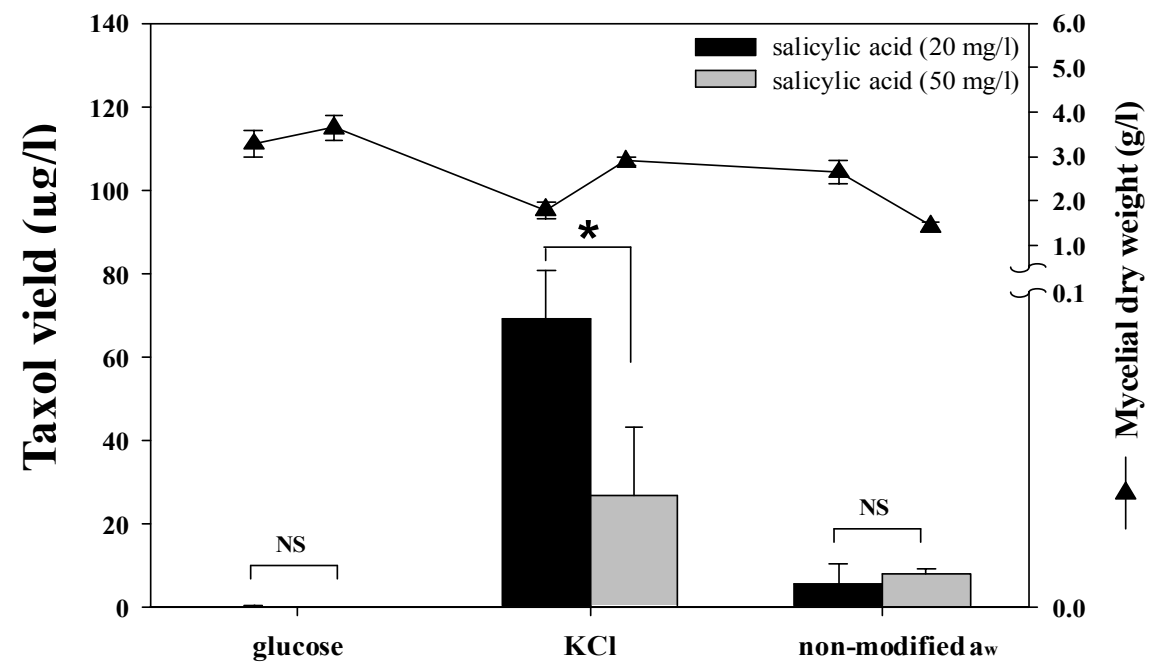

(b) $\mathrm{pH}$

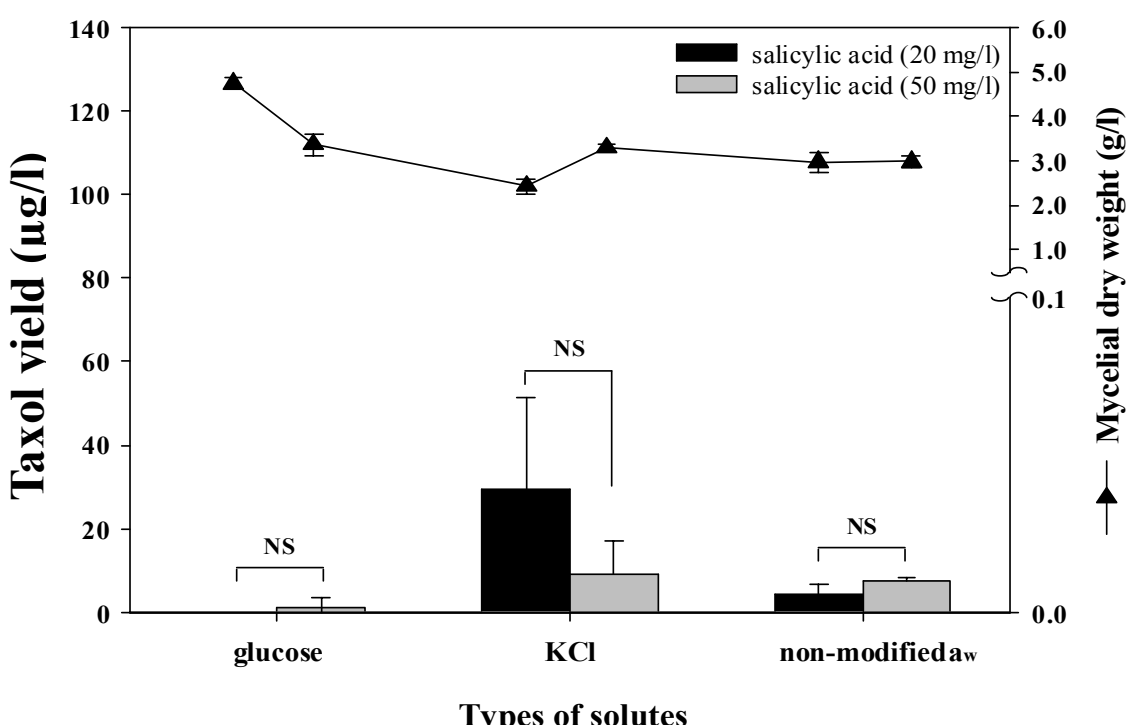

Figure 3 The effect of the different concentrations of salicylic acid, water activity $\left(\mathrm{a}_{\mathrm{w}}\right)$, solutes and $\mathrm{pH}$ on taxol production and mycelial dry weights of $P$. variabile. Two different $\mathrm{pH}$ levels were used: (a) $\mathrm{pH} 5$, (b) $\mathrm{pH}$ 6. The $\mathrm{a}_{\mathrm{w}}$ of media were modified with glucose and $\mathrm{KCl}$ to 0.98 . Data are presented as the mean \pm S.D. from three replicates. An asterisk indicates significant differences $(\mathrm{P}<0.05$, Student's t-test); NS, no significant difference. 
(a)

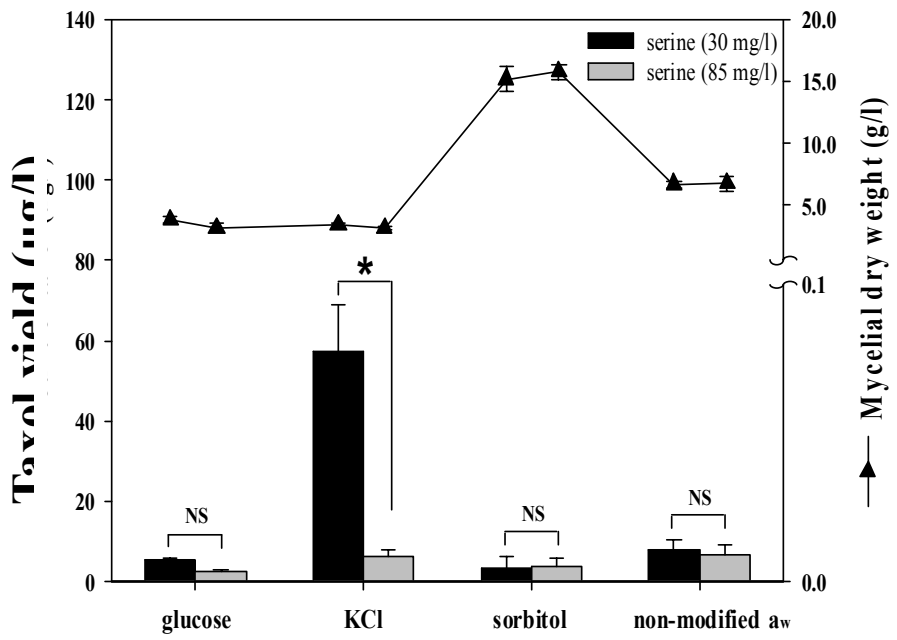

(b)

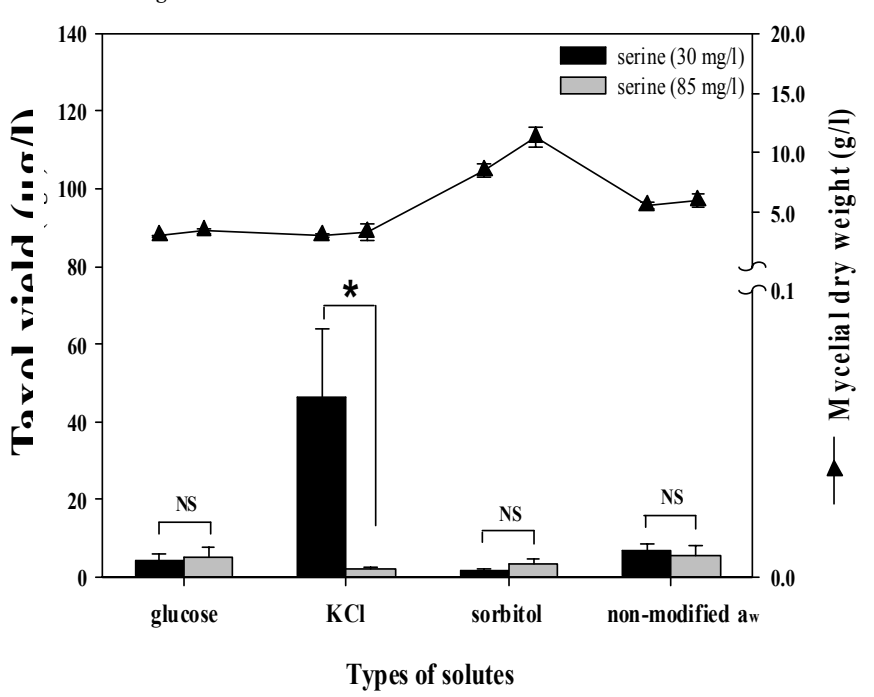

Figure 4. The effect of the different concentrations of salicylic acid, water activity $\left(a_{w}\right)$, solutes and $\mathrm{pH}$ on taxol production and mycelial dry weight of E. nigrum. Two different $\mathrm{pH}$ levels were used: (a) $\mathrm{pH} 5$, and (b) $\mathrm{pH}$ 6. The $\mathrm{a}_{\mathrm{w}}$ of media were modified with glucose, $\mathrm{KCl}$ and sorbitol to 0.98 . Data are presented as the mean \pm SD from three replicates. An asterisk indicates significant differences $(\mathrm{P}<0.05$, Student's t-test $) ; \mathrm{NS}$, no significant difference. 


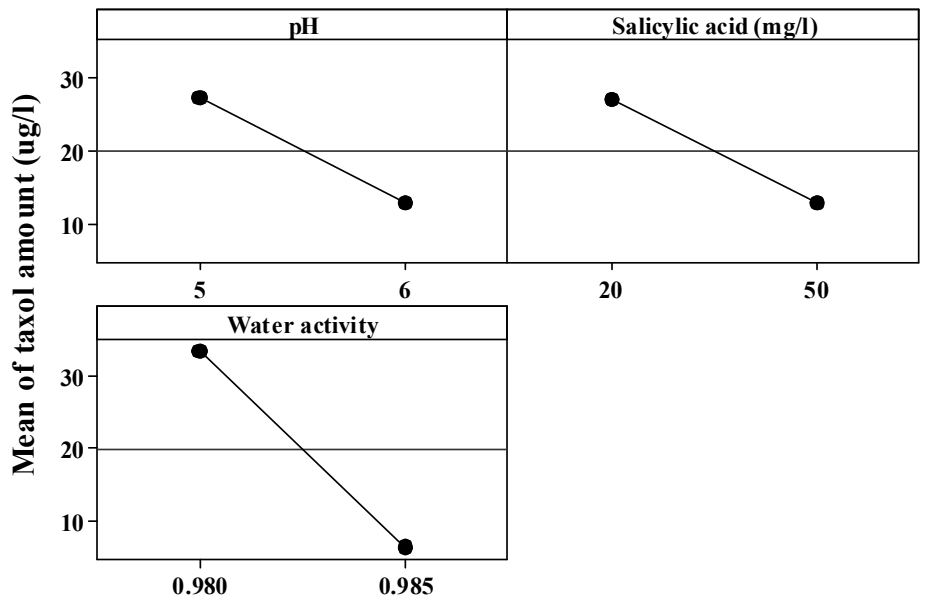

Figure 5. Main effects plot for (a) $\mathrm{pH}$, (b) salicyclic acid and (c) water activity on the mean taxol yield $(\mu \mathrm{g} / \mathrm{l})$ in liquid cultures of $P$. variabile. 


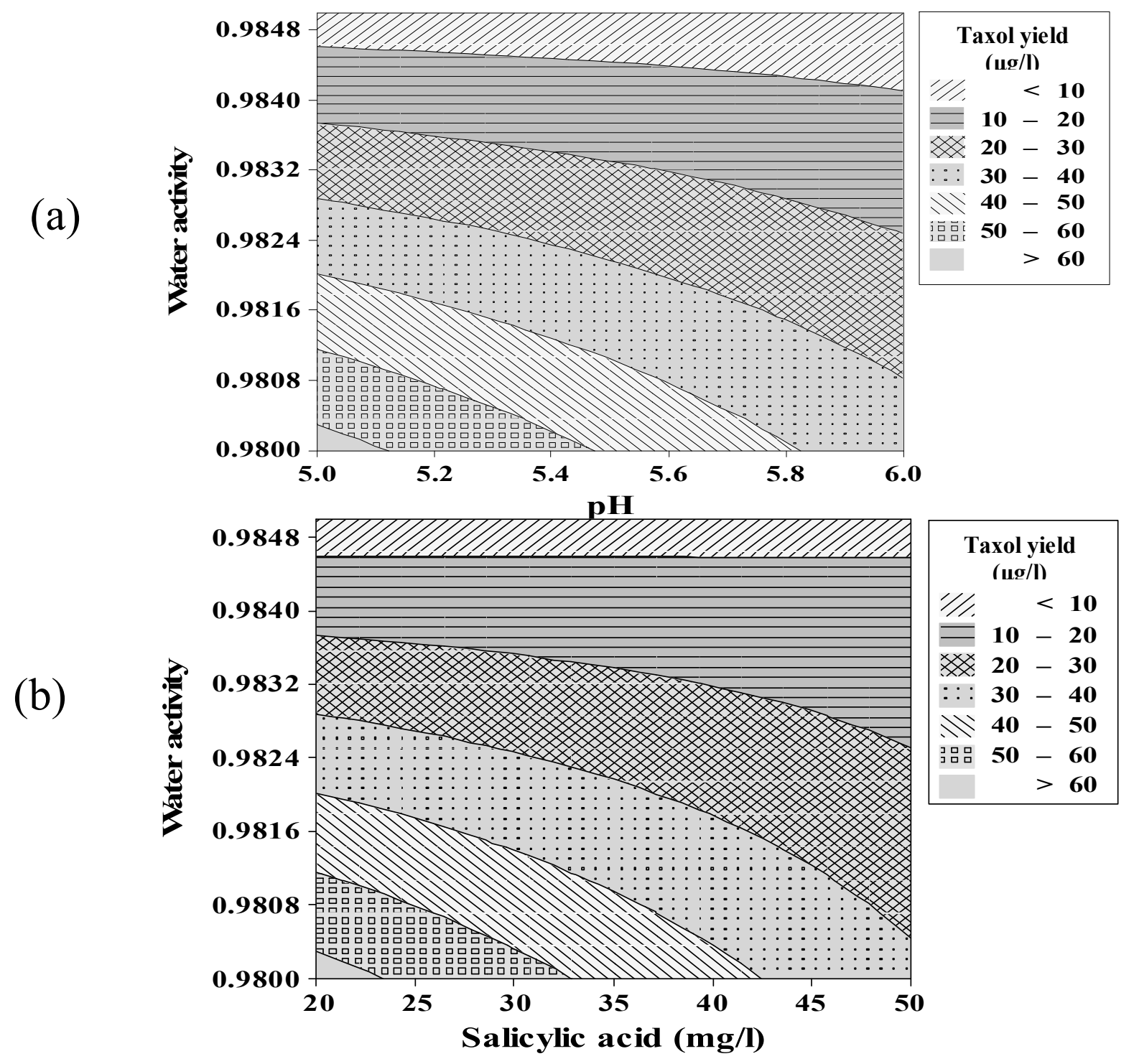

Figure 6. Somjaipeng et al.

Figure 6. The contour plot for (a) taxol yield as a function of $\mathrm{pH}$ and water activity $\left(\mathrm{a}_{\mathrm{w}}\right)$ with a fixed factor of the elicitor salicylic acid concentration at $20 \mathrm{mg} / \mathrm{l}$ and (b) for taxol yield as a function of $\mathrm{a}_{\mathrm{w}}$ and salicylic acid concentration with $\mathrm{pH} 5$ as the fixed factor for $P$. variabile. 


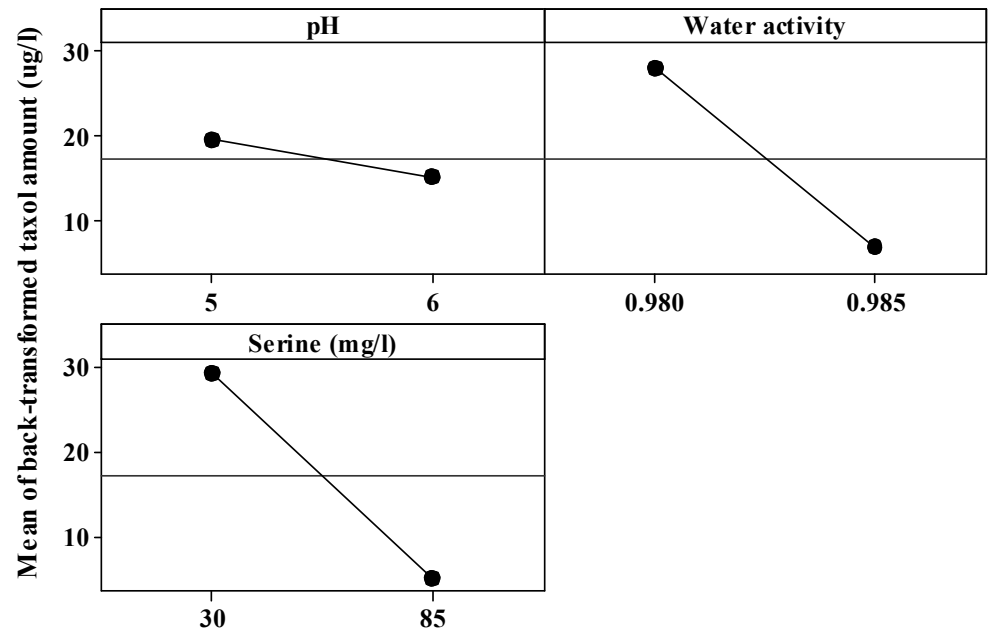

Figure 7. Main effects plot for (a) $\mathrm{pH}$, (b) water activity and (c) serine on the mean taxol yield ( $\mu \mathrm{g} / \mathrm{l})$ in liquid cultures of E. nigrum.

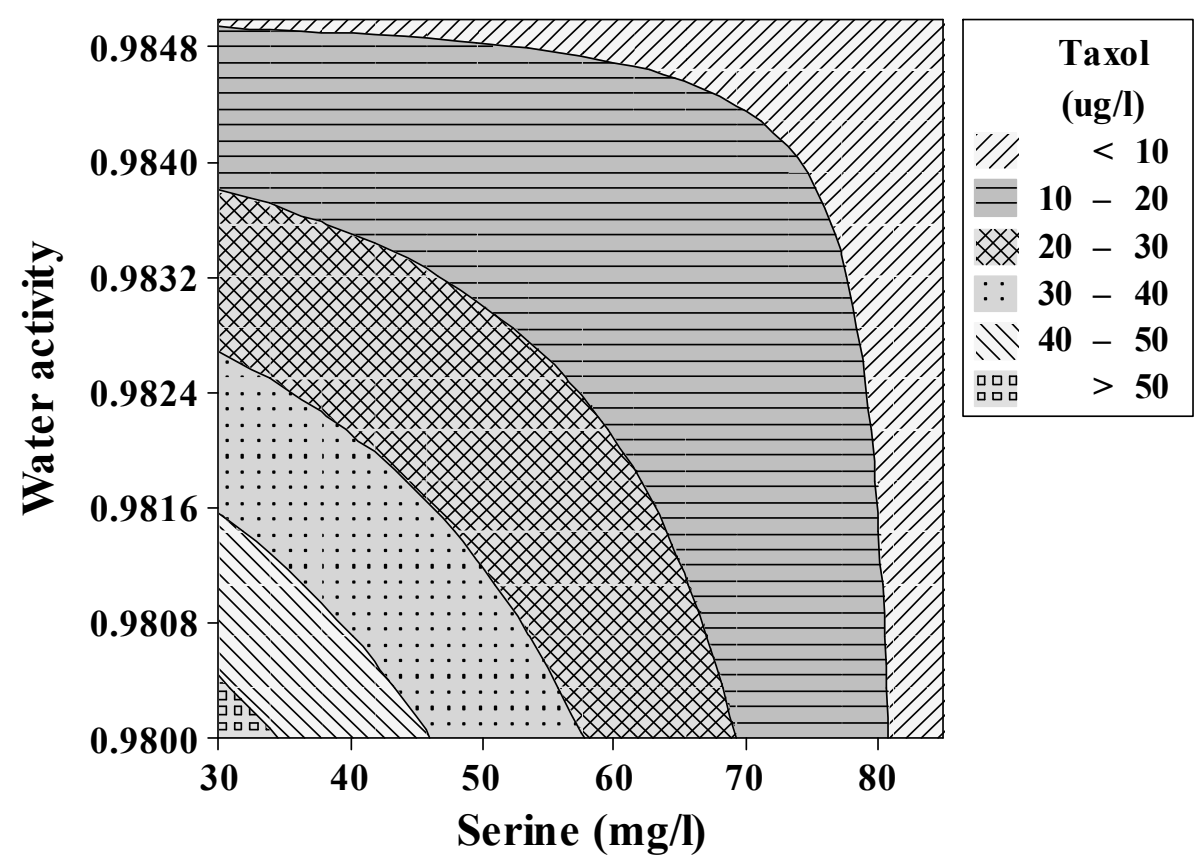

Figure 8 . The contour plot for the effect of the interaction between water activity $\left(\mathrm{a}_{\mathrm{w}}\right)$ and serine concentration on back-transformed taxol yield $(\mu \mathrm{g} / \mathrm{l})$ for E. nigrum. The $\mathrm{pH}$ was held at 5.0. The original statistical analysis was performed on the transformed data sets. 